\title{
Simulation of Constant Kinetic Energy Striking of Non-lethal Weapons' Interior Ballistics
}

\author{
Xiaojun Zhai, Li Pu*, Xianpei Jiang and Yongjie Zhu \\ Equipment Engineering Institute, Engineering University of CAPF, Xi'an 710086, China \\ 314576171@qq.com
}

Keywords: Constant kinetic energy strike; Interior ballistics; Simulation

\begin{abstract}
This paper applies the Runge-Kutta and Lax-Wendroff to handle the interior ballistic model, which is based on the quasi two-phrase flow of the interior ballistic model as well as the theory of variable velocity shooting and constant kinetic energy striking of non-lethal destruction. Under the circumstance of Matlab, and also analysis the rule of initial velocity which is influenced by the parameter changes of the frustrated chamber hole, frustrated chamber as well as gas chamber hole and receives a set of parameter which constant kinetic energy strike effect is more satisfactory. Compared to the result of the simulation, it verifies the accuracy of the model and provides the basis for the further development of using non-lethal weapons with the constant energy.
\end{abstract}

\section{Introduction}

Recent years, with the development of economic and society, security situation in domestic and overseas is more and more serious. As the ongoing major terrorist events and violence affairs in domestic and overseas, its damage and destruction is becoming more and more serious. So various of new baton gun comes out. These kind of weapon can not only help individual soldier handle the target effectively, but also can control the damage within certain limits .For example, American variable speed rifle system(Variable Velocity Rifle System) (VVRS) [1], Belgium FN303 low splash emitter and Beretta company's Constant kinetic energy system (lethal 7000) [2] etc..

The effect of constant energy attack system is generated by the end of the projectile kinetic energy can create a certain degree damage without fatal or disabling effect to the target. The projectile attack kinetic energy, the target and the environment interact with each other. Different target and environment require different attack kinetic energy. However, in the actual process, the target is active, its corresponding striking distance is changing according to the target's moving. Different distance requires different attack kinetic. Too high or low initial speed all can cause unsatisfying non-fatal effect. So, make the weapon constant energy attack come true is the key point of non-fatal effect.

In this article, we accomplish varying muzzle velocity shooting and effect seted non-fatal damage by the principle of releasing of part of the promoted gas to reduced chamber pressure [3]. With computer simulating the interior ballistic of weapon system, we make a conclusion that the projectile muzzle velocity is changed with the variation of opening number, location, size and exhaust port size, and promote the development of baton gun constant energy attack system.

\section{Interior Ballistics Model}

In this paper, the hypothesis is based on interior ballistics theory, combine with quasi-two-phase, interior ballistics characteristic of certain riot gun [4]. With chamber interior ballistics basic equation combined with air relative flow equation and relative temperature equation, we set up the mode of interior ballistics mathematical model of this variable muzzle velocity way: 


$$
\left\{\begin{array}{l}
\frac{d p}{d t}=\frac{1}{A\left(l+l_{\psi}\right)} \times \\
\left\{f \omega \frac{d \omega}{d t}-f q_{m 1}-A p\left[(k-1) v+\frac{d l}{d t}+\frac{d l_{\psi}}{d t}\right]\right\}, \\
\frac{d l}{d t}=v, \\
\frac{d v}{d t}=\frac{A p}{\varphi m}, \\
\frac{d \psi}{d t}=\chi \frac{d Z}{d t}+2 \chi \lambda Z \frac{d Z}{d t}
\end{array}\right.
$$

In this equation: $p$ is the inside chamber pressure; $f$ is powder power; $A$ is chamber section surface; $l$ is bullet moving location; $l_{w}$ is powder room volume reducing length; $w$ is powder weight; $q_{m l}$ is the gunpowder air volume in air room form exhaust port; $m$ is projectile weight; $v$ is projectile moving speed; $\psi$ is fired gunpowder weight score; $\phi$ is resistance factor; $x$ and $\lambda$ are gunpowder shape factor; $Z$ is relative gunpowder fired thickness.

\section{Numerical Solution}

Numeric Calculation. We use the mathematical model (1) as the interior ballistic simulation mathematical model of a barrel exhaust port variable muzzle velocity ways. Using classical runge-kutta algorithm in MATLAB environment, it is concluded the influence to projectile muzzle velocity with different position of frustrated hole, different number of exhaust port, different area of exhaust port. Also, we compare it with theory data, validate with model to examine the accuracy of this model.

The interior ballistic mathematical model is transformed in conservation matrix form [5]

$$
\frac{\partial U}{\partial t}+\frac{\partial F(U)}{\partial x}=H
$$

Difference Scheme and Stability Conditions. In general, the mathematical model of quasi-two-phase interior ballistic is a mixture of hyperbolic parabolic partial differential equation. Normally it can only be approximate solved by the method of a number instead of an analytic solution. At present, the commonly used numerical method of interior ballistic are grid difference method and characteristic line. Characteristic line is generally applied to hyperbolic equations, so for interior ballistic calculation, grid difference is commonly used. With the Lax-Wendroff format [6], the L-W difference scheme of equation (2) is:

(1) Prediction step:

$$
U_{i+1 / 2}^{n+1 / 2}=\frac{1}{2}\left(U_{i+1}^{n}+U_{i}^{n}\right)-\frac{\Delta t}{2 \Delta x}\left[F(U)_{i+1}^{n}-F(U)_{i}^{n}\right]+\frac{\Delta t}{2} H_{i+1 / 2}^{n}
$$

among them, i, n take $0,1,2 \ldots$ (2) Adjusting step:

$$
U_{i}^{n+1}=U_{i}^{n}-\frac{\Delta t}{\Delta x}\left[F(U)_{i+1 / 2}^{n+1 / 2}-F(U)_{i-1 / 2}^{n+1 / 2}\right]+\Delta t H_{i}^{n+1 / 2},
$$

Among them,

$$
H_{i+1 / 2}^{n}=\frac{1}{2}\left(H_{i+1}^{n}+H_{i}^{n}\right), H_{i}^{n+1 / 2}=\frac{1}{2}\left(H_{i+1 / 2}^{n+1 / 2}+H_{i-1 / 2}^{n+1 / 2}\right) \text { 。 }
$$

The stability condition of L-W format is

$$
(|u|+c) \frac{\Delta t}{\Delta x} \leq 1
$$

So, when $\Delta \mathrm{x}$ is taken, time length $\Delta \mathrm{t}$ should comply with the stability condition:

$$
\Delta t \leq \frac{c_{0} \Delta x}{|u|+c}
$$

In the equation: $c_{0}$ is a coefficient small than 1 , normally take $0.8 \sim 0.9, u$ is mixed phase velocity in chamber, $c$ is sound speed. 
The Initial Conditions and Boundary Conditions. The shooting time is the initial condition. At this point, the gas-solid two phase velocity are zero, the pressure is atmospheric pressure, temperature is the environment temperature, and density is determined by state equations.

1) left boundary----chamber bottom boundary conditions

If not considering the impact of blow-back, the chamber bottom is treated as still solid wall, for this kind of boundary is usually adopt the second grid as the reflection method which is more convenient [6].

2) Right boundary---projectile bottom motion boundary

For this kind of motion boundary, the motion controlling method can be used to deduce the conservation type format.

When projectile is moving off the exhaust port range, the mathematical equation is:

$$
\rho_{2}=\frac{\rho_{1} d x_{1}+\rho_{N-1} u_{N-1} \Delta t}{d x_{2}}
$$

In the equation, $\mathrm{N}$ and $\mathrm{n}$ of formula (3) are specular reflection:

When projectile is moving in the exhaust port range, the mathematical equation is:

$$
\rho_{2}=\frac{\rho_{1} A d x_{1}+\rho_{N-1} u_{N-1} A \Delta t-\frac{m}{2 r} \cdot \frac{d x_{1}+d x_{2}}{2} \Delta t}{A d x_{2}},
$$

All the other data can be calculated directly by the formula.

\section{The Analysis of Simulation Results}

Take a certain type domestic18.4 mm riot gun as an example, the basic parameters are shown in Table 1.

Table 1.The basic parameters of certain type domestic $18.4 \mathrm{~mm}$ riot gun [7]

\begin{tabular}{|c|c|c|c|}
\hline Caliber $d / \mathrm{cm}$ & $\begin{array}{c}\text { Section surface } \\
A / \mathrm{cm}^{2}\end{array}$ & Projectile weight $\mathrm{m} / \mathrm{kg}$ & Powder weight $\omega / \mathrm{kg}$ \\
\hline 1.84 & 2.65 & 0.022 & 0.0015 \\
\hline $\begin{array}{c}\text { Powder room } \\
\text { volume } W_{0} / \mathrm{cm}^{3}\end{array}$ & $\begin{array}{c}\text { Air room volume } \\
W_{l} / \mathrm{cm}^{3}\end{array}$ & $\begin{array}{c}\text { Pushing resistance } \\
P / \mathrm{MPa}\end{array}$ & $\begin{array}{c}\text { Gunpowder density } \\
\delta / \mathrm{kg}^{-3} \mathrm{~m}^{-3}\end{array}$ \\
\hline 3.85 & 63 & 5 & 1600 \\
\hline $\begin{array}{c}\text { Barrel length } \\
l_{\text {xc }} / \mathrm{cm}\end{array}$ & $\begin{array}{c}\text { Gunpowder power } \\
f / \mathrm{J} \times \mathrm{kg}^{-1}\end{array}$ & Air residue volume $\alpha$ & $\begin{array}{c}\text { Gunpowder thickness } \\
2 e_{1} / \mathrm{cm}\end{array}$ \\
\hline 38.02 & 900000 & 0.001 & 0.014 \\
\hline $\begin{array}{c}\text { Adiabatic exponent } \\
k\end{array}$ & $\begin{array}{c}\text { Resistance } \\
\text { coefficient } \varphi\end{array}$ & $\begin{array}{c}\text { Gunpowder shape } \\
\text { characteristic data }\end{array}$ & $\begin{array}{c}\text { Gunpowder shape } \\
\text { characteristic data }\end{array}$ \\
\hline 1.2 & 1.1 & 1.15 & -0.13 \\
\hline
\end{tabular}

Due to the shooting range of this weapon is $10 \sim 100 \mathrm{~m}$, according to injury standard of the riot kinetic energy bullet, and combined with its outer ballistic model, it is calculated the theoretical muzzle velocity range are shown in Table 2 . In this paper, it is taken computer simulation analyzed in the condition that an air hole is made, on this type riot gun pipe, and connecting with the air room, also takes an example of the kinetic energy pain block bullet in the condition of shooting certain loaded gunpowder. It made the riot gun can be energy controlled within the scope of $10 \sim 100 \mathrm{~m}$ and achieve the non-fatal attacking at the end. 
Table 2.The projectile muzzle velocity in different kinetic energy standard and distance

\begin{tabular}{|c|c|c|c|}
\hline $\begin{array}{c}\text { Aim distance } \\
x / \mathrm{m}\end{array}$ & $\begin{array}{c}\text { Kinetic energy } \\
\text { standard E/J }\end{array}$ & $\begin{array}{c}\text { Kerma standard } \\
E_{\mathrm{b}} / \mathrm{J} \times \mathrm{cm}^{-2}\end{array}$ & $\begin{array}{c}\text { Projectile muzzle } \\
\text { velocity v/m } \times \mathrm{s}^{-1}\end{array}$ \\
\hline 10 & 88.0 & 71.7 & 89.0 \\
\hline 20 & 90.8 & 74.0 & 90.4 \\
\hline 30 & 93.7 & 76.3 & 91.9 \\
\hline 40 & 96.7 & 78.7 & 93.3 \\
\hline 50 & 99.7 & 81.1 & 94.8 \\
\hline 60 & 102.9 & 83.6 & 96.3 \\
\hline 70 & 106.1 & 86.1 & 97.8 \\
\hline 80 & 109.4 & 88.7 & 100.3 \\
\hline 90 & 112.9 & 91.4 & \\
\hline
\end{tabular}

First, simulation analysis to the interior ballistic in condition of exhaust port closed. Refer to Fig. $1 \sim 4$.

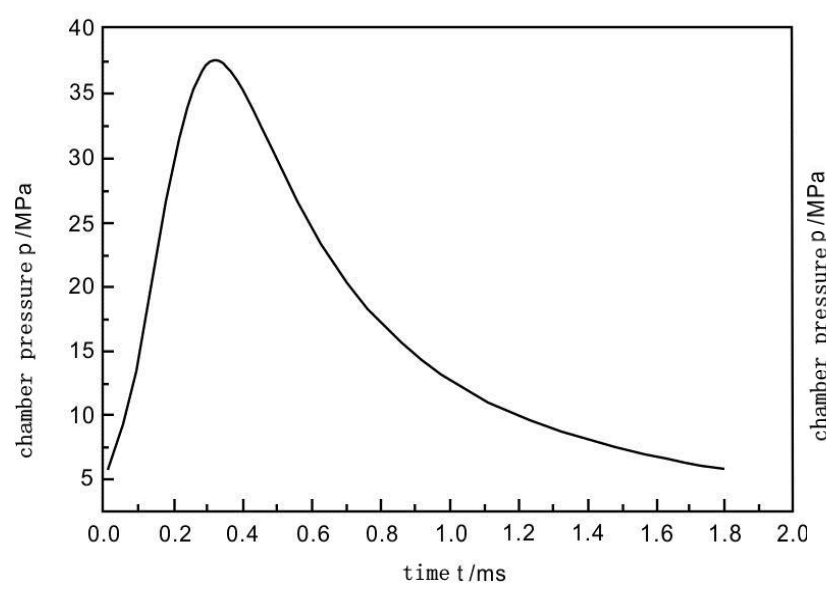

Figure 1. Inner trajectory chamber pressure in chamber is changing with time

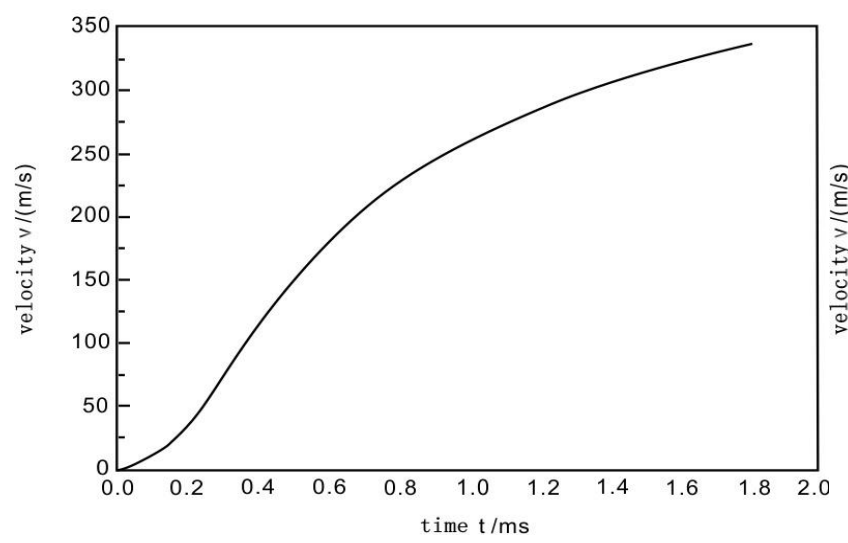

Figure 3. Projectile speed is changing with time

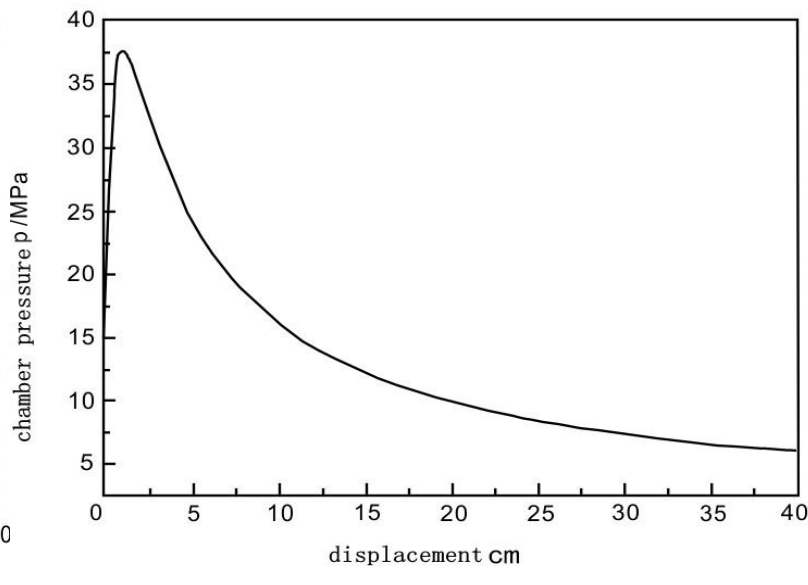

Figure 2. Inner trajectory chamber pressure is changing with projectile location

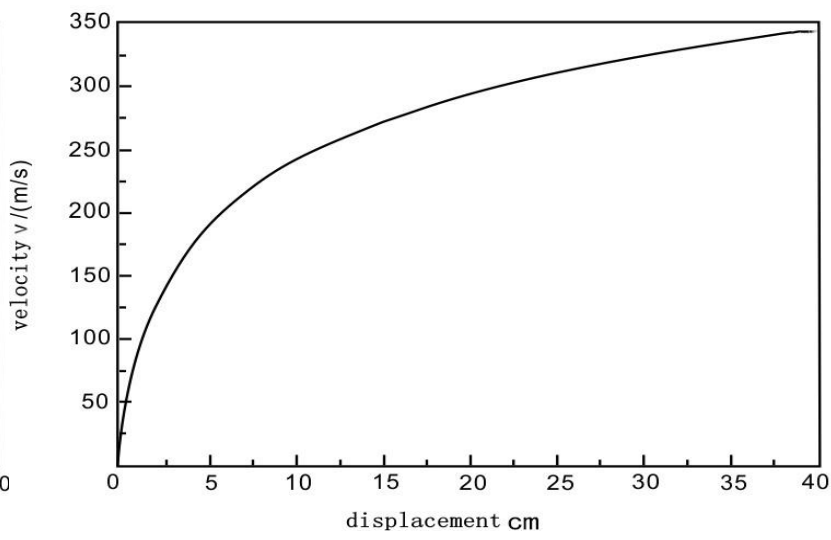

Figure 4. Projectile speed is changing with motion

Form Fig. 1 4, it is concluded that when the projectile moved to $0.32 \mathrm{~ms} 、 0.9 \mathrm{~cm}$, the chamber pressure reach the $37.6 \mathrm{MPa}$ which is the highest; the projectile out of chamber speed is $330.1 \mathrm{~m} / \mathrm{s}$, the motion time within chamber is $1.7 \mathrm{~ms}$, and the speed is rising the fastest within the former $50 \mathrm{~mm}$.

The Impact of Exhaust Port Number on Projectile Muzzle Velocity. The exhaust hole number is refer to the number of exhaust port on gun pipe. When making hole on gun pipe, it is set 
that single hole area is $30 \mathrm{~mm}^{2}, 40 \mathrm{~mm}$ to chamber bottom, exhaust port volume is $60 \mathrm{~cm}^{3}$, air room diameter is $12 \mathrm{~mm}$, distance between holes keep unchanged, number increased in turn. By computer simulation, the projectile muzzle velocity is worked out, with comparing with the experiment measured muzzle velocity, the relationship between hole number and projectile muzzle velocity is work out (refer to Table 3).

Table 3.the relationship between hole number and projectile muzzle velocity

\begin{tabular}{|c|c|c|}
\hline Hole number & Simulation value $/ \mathrm{m} \times \mathrm{s}^{-1}$ & Test value $/ \mathrm{m} \times \mathrm{s}^{-1}$ \\
\hline 0 & 330.1 & 340.6 \\
\hline 1 & 289.5 & 295.2 \\
\hline 2 & 264.8 & 272.9 \\
\hline 3 & 254.7 & 253.5 \\
\hline
\end{tabular}

It is can be concluded form Table 3 that projectile muzzle velocity reduced obviously when there's exhaust hole on gun pipe. The more exhaust hole the slower projectile muzzle velocity. As the gun pipe is fixed, and the valid shooting range of this type riot gun is $10-100 \mathrm{~m}$, so the number of exhaust hole is fixed. Usually, 3 holes can satisfy this weapon system to work well.

The Impact of Exhaust Hole Location on Projectile Muzzle Velocity. When the exhaust hole area is $30 \mathrm{~mm}^{2}$, discuss the regulation of chamber pressure, projectile muzzle velocity and location motion in 4 kind of hole location $(40 \mathrm{~mm}, 60 \mathrm{~mm}, 80 \mathrm{~mm}$ and $100 \mathrm{~mm}$ ), with other parameter unchanged. The relationship between exhaust hole location and projectile muzzle velocity by computer simulation are shown in Fig.5 8.

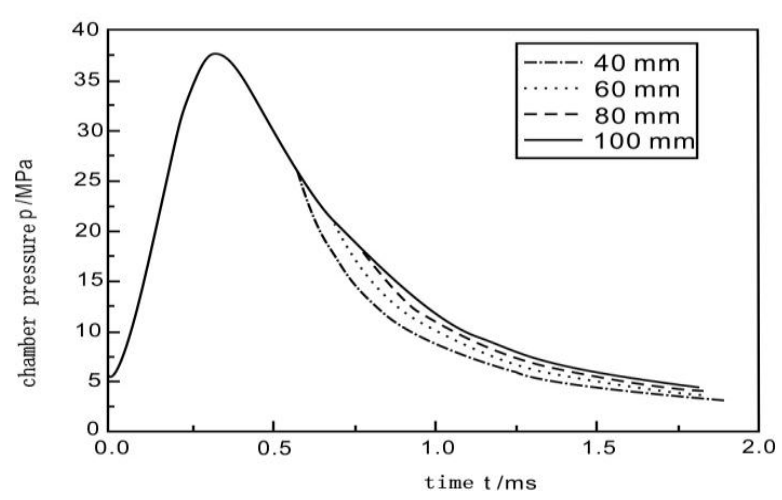

Figure 5. Riot gun chamber pressure is changing with time

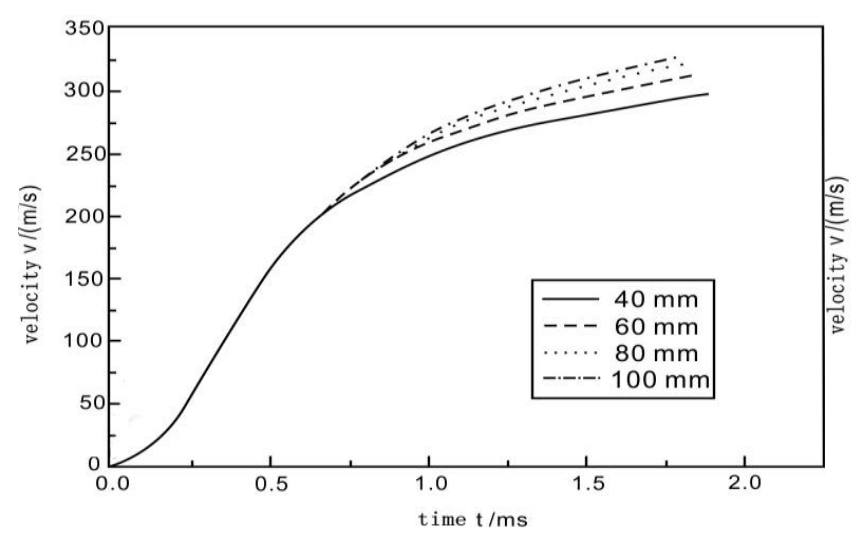

Figure 7. Projectile speed is changing with time

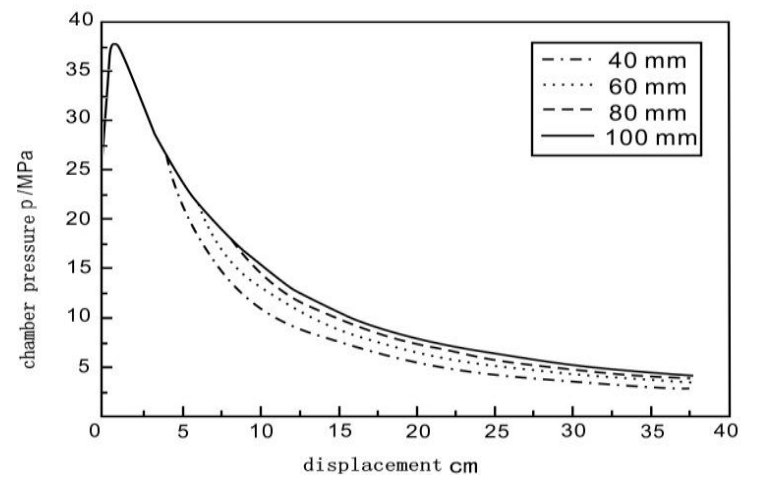

Figure 6. Riot gun chamber pressure is changing with location

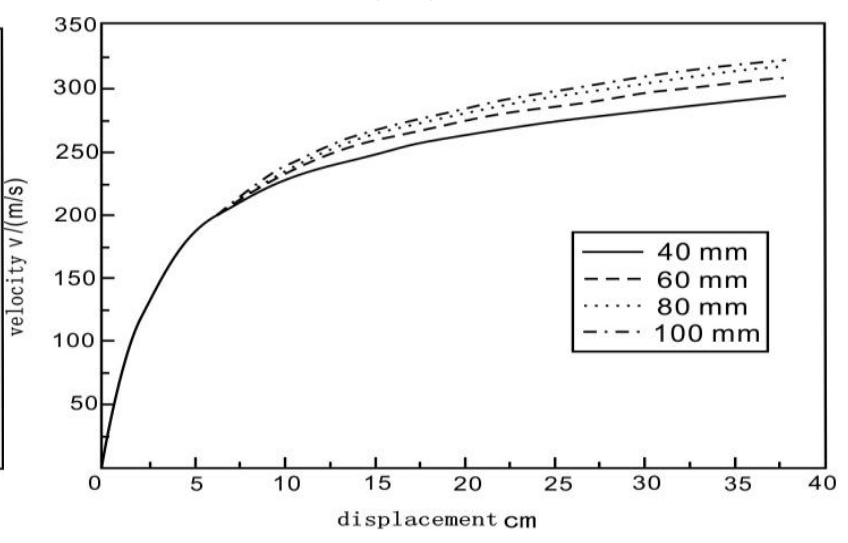

Figure 8. Projectile speed is changing with location 
It is obviously concluded form Fig.5 and 6 that, after projectile passed exhaust hole, the gunpowder air discharged form exhaust hole, the closer of the hole to highest chamber pressure, the obvious of chamber reduce; the far of hole to highest chamber pressure, the un-obvious of chamber reduce. It is concluded from Fig.7 and 8 that the closer of between holes, the earlier of gunpowder air discharge and chamber pressure reduce, the obvious of chamber pressure reduce scope and projectile muzzle velocity reduce; the far between holes, as the small chamber pressure reduce cope leads muzzle velocity reduce not obvious. And when the distance is $40 \mathrm{~mm}$, the projectile muzzle velocity is the most obvious. But according to the character of riot gun kinetic energy pain block bullet, the bullet length is about $65 \mathrm{~mm}$, with projectile sealing impacted by gunpowder air, it's about $70 \mathrm{~mm}$ after unfolded. Combining with test operating, if the hole is made the location of $40 \mathrm{~mm}$, if will block the exhaust and lead the gunpowder air cannot be discharged, so the hole location near the $80 \mathrm{~mm}$ is more appropriate.

The Impact of Exhaust Area on Projectile Muzzle Velocity. The exhaust hole location is fixed on $80 \mathrm{~mm}$, change exhaust hole diameter, discuss the muzzle velocity changing regulation with the change of time and location in 5 hole areas $\left(30 \mathrm{~mm}^{2}, 60 \mathrm{~mm}^{2}, 90 \mathrm{~mm}^{2}, 120 \mathrm{~mm}^{2}\right.$ and $150 \mathrm{~mm}^{2}$ ), without changing other parameter, by computer simulation , the relationship between exhaust area and projectile muzzle velocity are shown in Fig. 9 and 10.

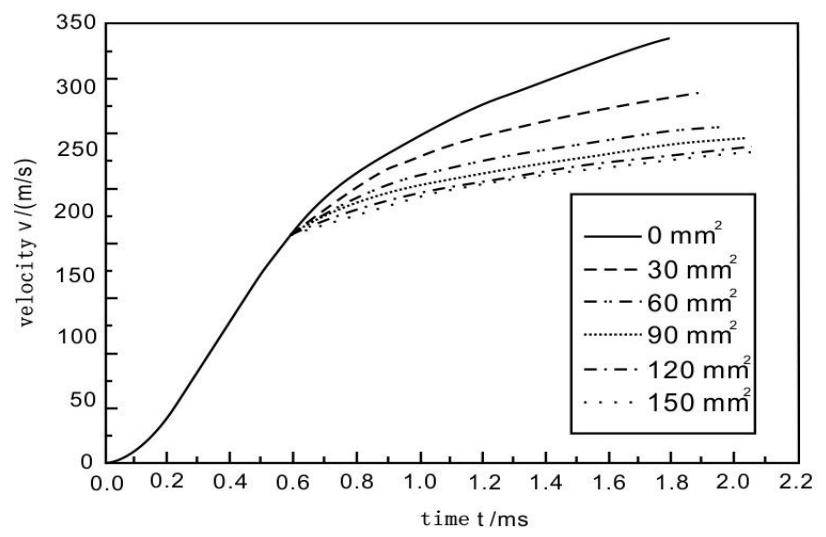

Figure 9. Projectile speed is changing with time

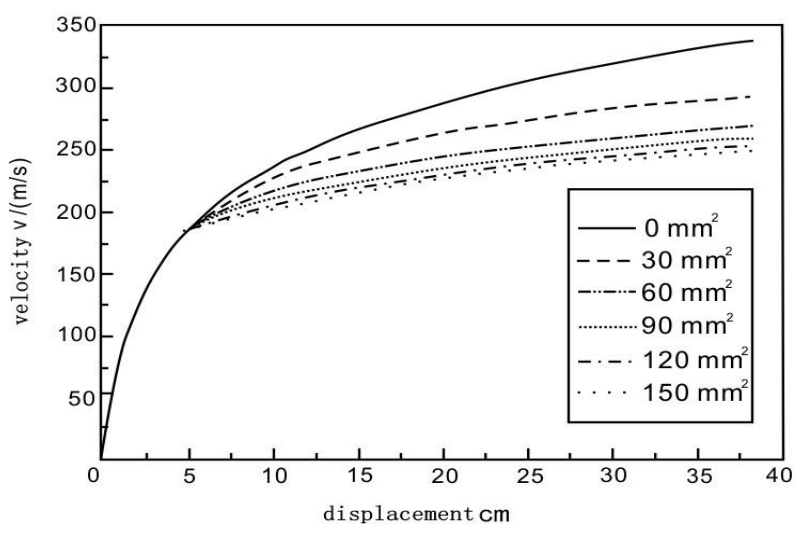

Figure 10. Projectile speed is changing with location

When the projectile passed exhaust hole, the gunpowder passed exhaust hole and discharged leading the chamber pressure reducing, the pushing power for projectile moving is reduced, the time for projectile moving in chamber is increased. The larger of hole area, the more gunpowder air is discharged in unit time, the lager scope of chamber pressure reducing; when the hole area is little, the chamber pressure changing scope is also sensitive to the changing scope of area. It is concluded form Fig. 9 and 10 that, when the hole area are $30 \mathrm{~mm}^{2}$ and $60 \mathrm{~mm}^{2}$, the muzzle velocity reducing scope is larger; when the hole area is $90 \mathrm{~mm}^{2}, 120 \mathrm{~mm}^{2}$ and $150 \mathrm{~mm}^{2}$, velocity reducing scope is little. And when the hole area is $30 \mathrm{~mm}^{2}$, the velocity reducing scope is the most obvious.

The Impact of Exhaust Port Volume on Projectile Muzzle Velocity. The exhaust hole location is fixed on $80 \mathrm{~mm}$, hole area is $30 \mathrm{~mm}^{2}$, change the volume of exhaust port, discuss the muzzle velocity changing regulation with the changing of time and location in 5 exhaust port volume $\left(10 \mathrm{~cm}^{3}, 40 \mathrm{~cm}^{3}, 80 \mathrm{~cm}^{3}, 120 \mathrm{~cm}^{3}\right.$ and $\left.150 \mathrm{~cm}^{3}\right)$, without changing other parameter, by computer simulation, the relationship between exhaust port volume and projectile muzzle velocity are shown in Fig. 11 and Fig. 12. 


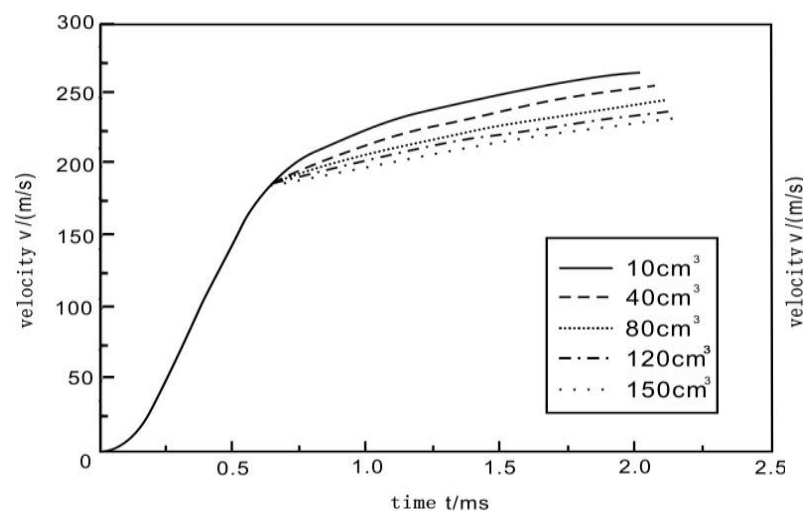

Figure 11. Projectile speed is changing with time

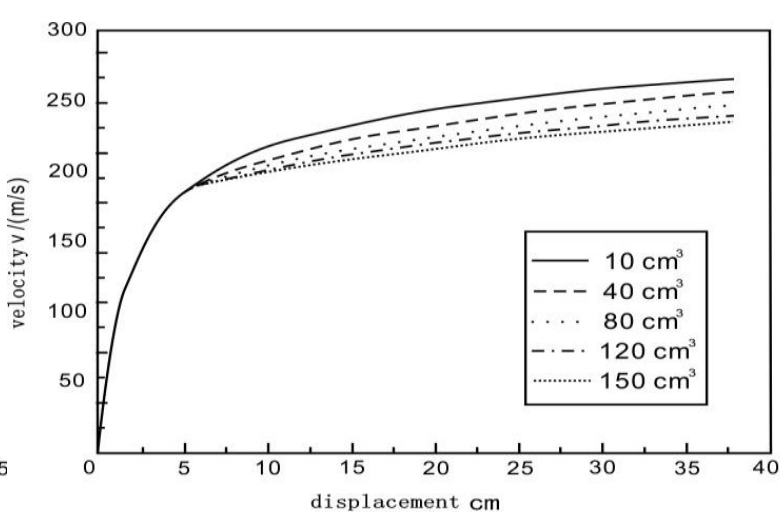

Figure 12. Projectile speed is changing with location

It is concluded from Fig. 11 and 12 that the smaller of the exhaust port, as the chamber pressure reducing scope is smaller, the projectile muzzle velocity being faster; the bigger of exhaust port volume, the bigger of chamber pressure reducing scope, the projectile muzzle velocity being slower. But when the exhaust volume is big enough to a certain extent, the impact of volume changing to chamber pressure is really small. When the exhaust port volume is $10 \mathrm{~cm}^{3}$, the projectile muzzle velocity is the fastest; when the volume is $150 \mathrm{~cm}^{3}$, the projectile is the slowest.

The Impact of Air Room Area on Projectile Muzzle Velocity. Make an air room hole on exhaust port, it will directly impact on the exhaust pressure, and chamber pressure indirectly, and impact on projectile muzzle velocity. When the air room is $30 \mathrm{~mm}^{2}$, without changing the other parameters, change air room hole area, by computer simulation, the relationship between air room area and projectile muzzle velocity is shown in Fig. 13.

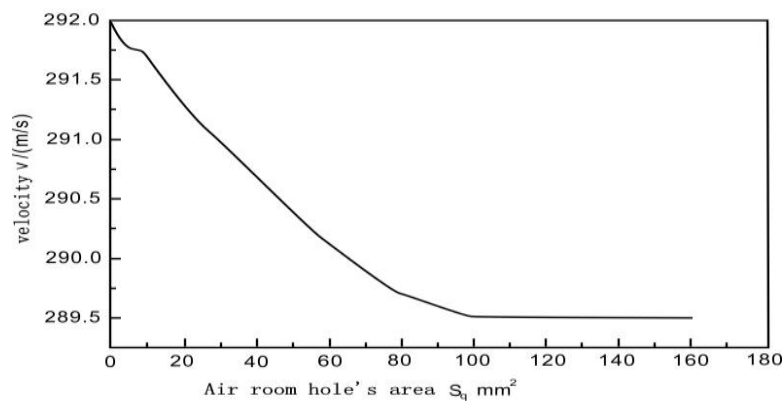

Figure 13. Projectile muzzle velocity is changing with air room hole

It is concluded from Fig. 13 that, when the air room area is $0 \mathrm{~mm}^{2}$, exhaust port is sealed, gunpowder air can only moving between gun chamber and exhaust port, the gunpowder air can be discharged to the air; when the air room between $0 \mathrm{~mm}^{2} \sim 100 \mathrm{~mm}^{2}$, the bigger of air room hole area, the more gunpowder air will be discharged into the air in unit time, the pressure of exhaust port will be much lower, and the difference between chamber pressure and exhaust port pressure will be much bigger, this will lead more gunpowder air discharged to exhaust port form chamber in unit time, the chamber pressure will be much lower, the pushing power for projectile forwarding will be much smaller, at last, the projectile muzzle velocity will be much slower. When air room hole area is more than $100 \mathrm{~mm}^{2}$, the impact of the rising air room area on exhaust port pressure is reducing gradually, the projectile muzzle velocity will be with no change correspondingly.

\section{Conclusion}

In this paper, according to classical interior ballistics theory and quasi-two-phase interior ballistics model, combining with gas dynamics, we set the $18.4 \mathrm{~mm}$ riot gun constant energy attacking system 
interior ballistics mathematical model. By the contacting between simulation test and theory data, it verifies the accuracy and reliability of the model. By computer simulation, the regulation of exhaust hole location, area and exhaust port area impact on projectile muzzle velocity. And it can be concluded from the above article that, when the exhaust hole distance is $80 \mathrm{~mm}, 30 \mathrm{~mm}^{2}$, the exhaust port is $150 \mathrm{~cm}^{3}$, the projectile muzzle velocity reduces the most, and the weapon constant energy attacking non-fatal effect is relatively ideal.

\section{References}

[1] Rongxuan Bian, Shoutao Sun. experting in one thing and good at many---FN303 weapon system [J], light weapon. 2004(11):26-28.

[2] Wenchao Zhu, Xiaobo Yang. Constant Fixed Non-fatal --BerettaLTLX7000 [J]. Light weapon. 2012(4):14-15.

[3] Jinglu Ran, Cheng Xu, Fuqiang Niu. Fixed effect non-fatal killing variable muzzle velocity shooting theory. Journal of Nanjing University of technology. Nature and science section. 2010, 34(6): 765-769.

[4] Tingyu Bao,Wenjian Qiu. Interior ballistics [M].Beijing: Beijing institute of technology press. 1995: 50-89,170-171.

[5] Chunsheng Weng, Hao Wang. Computational Interior Ballistics. Beijing: National Defend Industy Press. 2006:16-20.

[6] Zhiming Jin, Chunsheng Weng. Advanced interior Ballistics. Beijing: High Education Press.2003:185-186, 187-188, 189-190.

[7] Xudan Dong, Xiaojun Zhai. Research on Anti-riot Gun Development of Constant Terminal Effect. [J]. Technology Information 2012(3):106. 